\title{
Eighteenth-century forms of quasicrystals
}

\author{
Carlos M. Pina $^{\text {ab* }}$ and Victoria López-Acevedo ${ }^{\text {ac }}$ \\ ${ }^{a}$ Department of Crystallography and Mineralogy, Faculty of Geological Sciences, Complutense \\ University of Madrid, 28040 Madrid, Spain \\ ${ }^{\mathrm{b}}$ Geosciences Institute, IGEO (UCM-CSIC), 28040 Madrid, Spain \\ 'Museum of Geology at the Complutense University of Madrid, 28040 Madrid, Spain
}

Correspondence email: cmpina@geo.ucm.es

Synopsis This contribution analyses the symmetry of some crystal models published in 1783 by Romé de

L’Isle. Our analysis shows that such models have the external symmetry of quasicrystals.

\begin{abstract}
A careful inspection of the drawings and baked clay models created by the mineralogist Romé de L'Isle in the eighteenth century have revealed the existence of a number of intriguing forms with pentagonal symmetries. These forms cannot be classified in any of the thirty-two crystal classes. They can thus be considered first crystallographic descriptions of polyhedral forms found in quasicrystals two centuries later. Here we present a symmetry analysis of the fascinating drawings and clay models with pentagonal symmetries described in the book Cristallographie published in 1783 by Romé de L’Isle, as well as a comparison with quasicrystals recently synthesized. We also briefly discuss what could induce Romé de L'Isle to consider forms with pentagonal symmetries as plausible crystal forms.
\end{abstract}

Keywords: Quasicrystals; Crystallographic models; Romé de L’Isle; Symmetry analysis

The origin of modern Crystallography goes back to the first descriptions of polyhedral shapes found in minerals (Steno, 1669; Werner, 1774; Sequeiros, 2002). One of the aims of early crystal studies was to establish the laws governing the external polyhedra of minerals (Amorós, 1978 and references therein). First derivations of possible polyhedral shapes were essentially conducted by cutting vertices and bevelling edges of a number of crystal shapes which were considered as "primitives" (e.g. a cube). Remarkably, polyhedra derived following this method were related to crystal symmetry much later (Weiss, 1815), and only about two centuries after first systematic descriptions of mineral shapes, scientists confirmed that the external morphologies of crystals are determined by an internal structural order based on periodical patterns (Friedrich et al., 1912). The rigorous analysis of the possible threedimensional crystal shapes and internal patterns (i.e. lattices) led to the development of the 
current mathematical principles of Crystallography, whose milestones were: (i) the identification of the 32 crystal classes by Hessel $(1830,1897)$, (ii) the construction of the 14 lattices by Bravais (1850), and (iii) the deduction of the 230 space groups (Fedorov 1891; Schoenflies, 1891; Barlow 1883).

The discovery of quasicrystals has recently challenged the established principles of Crystallography (Shechtman, et al., 1984; Maciá, 2010). Unlike crystals, atoms in quasicrystal structures are not repeated periodically but according to aperiodic patterns mathematically related to tessellations previously described by Penrose (1974). This means that quasicrystals violate the crystallographic restriction theorem, which states that only twofold, three-fold, four-fold and six-fold rotational symmetries are compatible with a periodic arrangement of atoms in crystal structures (i.e. $2 \cos \theta=Z$; where $Z$ is integer and $\theta$ is the rotation angle corresponding to the symmetry axis). In other words, quasicrystals exhibit crystallographically “forbidden” external symmetries by sacrificing internal periodic order. The most common quasicrystals exhibit five-fold symmetries and they can be classified into nine quasicrystal classes (Rao, et al., 2007). These pentagonal quasicrystal classes describe all possible external symmetry of quasicrystals when five-fold axes are combined with mirror planes, two-fold and three-fold axes and a centre of symmetry. Unlike the thirty-two crystal classes, the quasicrystal classes are derived by neglecting the crystallographic restriction theorem.

In the eighteenth century, scientists began to describe and clasify the possible forms that crystals can exhibit in nature (Amorós, 1978; Kubbinga, 2001). This required an idealisation of the observed natural crystals, whose morphologies often deviated from regular polyhedra due to the unequal development of symmetrically equivalent faces. First descriptions of crystal forms and their classification in families paved the way for the development of modern Crystallography. However, early crystallographers considered that crystals with pentagonal symmetries were possible since the lattice theory of crystal structures had not been developed yet and, therefore, the crystallographic restriction theorem was unknown. In addition, the fascination with platonic solids since ancient times encouraged Romé de L'Isle and his contemporaries to look for regular dodecahedra and icosahedra within the mineral forms (Van Smaalen, 1995 and references therein).

In his book, Cristallographie (1783), Romé de L’Isle presented drawings of 448 crystal forms classified according to their geometrical and symmetrical analogies (Romé de L'Isle, 
1783). To make his book more commercially attractive, Romé de L'Isle sold it together with a collection of 448 crystal models nicely sculpted in baked clay (see Figure 1).


\section{Figure 1}

Two Photographs of a baked clay model of an elongated or pyramidal dodecahedron belonging to the collection of the Geology Museum at the Complutense University of Madrid (size of the model 2.5 $\mathrm{cm} \times 2.3 \mathrm{~cm}$ ). Left: lateral view; right: top view. According to Romé de L'Isle, this model reproduces a single crystal of marcassite from his personal mineral collection. Photographs by Toya Legido.

The National Museum of Natural Sciences in Madrid owns two second edition copies of Romé de L'Isle's Cristallographie and the Museum of Geology at the Complutense University of Madrid holds a large but incomplete collection of the accompanying crystal models (López-Acevedo \& de Dios Celada, 2012). Recently, a careful inspection of both drawings and the models by Romé de L'Isle revealed a fact: some of the models do not represent real crystals but forms typically shown by quasicrystals. In particular, Romé de L'Isle described two Platonic solids (i.e. the dodecahedron and the icosahedron), a pyramidal dodecahedron and a regular triacontahedron (see Figure 2). 


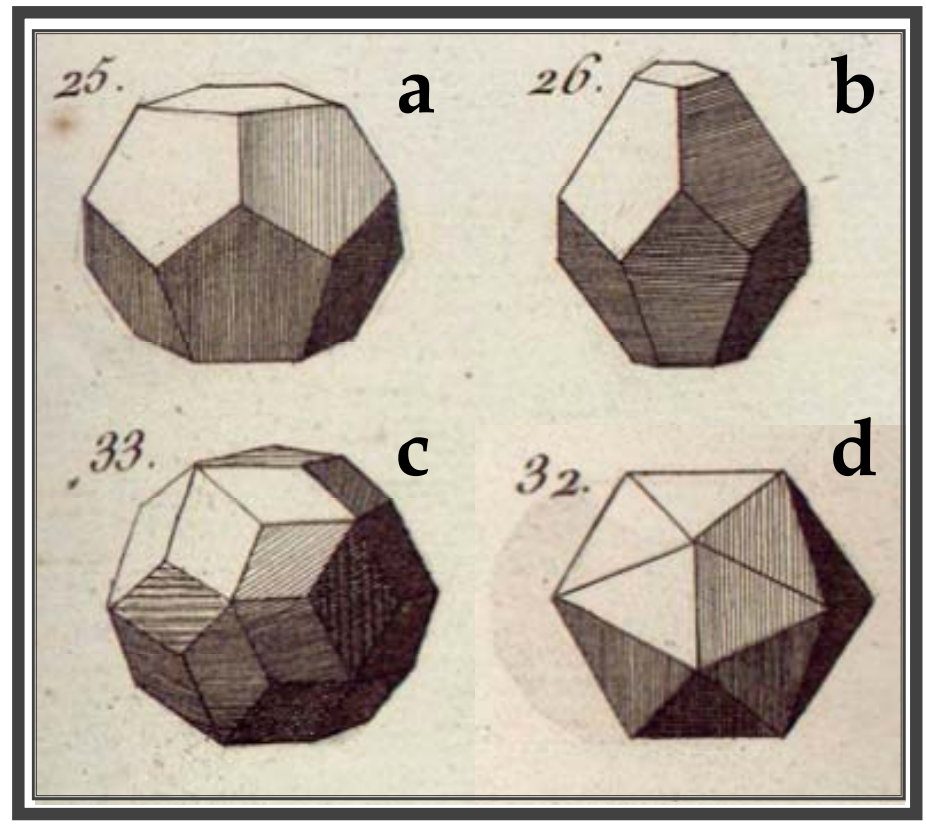

\section{Figure 2}

The "quasicrystal” models of Romé de L'Isle. a, regular dodecahedron. b, elongated or pyramidal dodecahedron. c, regular triacontahedron. d, icosahedron. Illustration adapted from Table II (Le Cube ou L'Hexaèdre et ses Modifications) in Volume IV of Cristallographie by Romé de L’Isle (1783).

Both the icosahedron and the regular triacontahedron are polyhedra formed by faceting the regular dodecahedron (see Figure 2 a, c and d). These three forms belong to the $\frac{2}{6 m} \overline{35}$ quasicrystal class and show an identical combination of symmetry elements: six five-fold roto-inversion axes, ten three-fold roto-inversion axes, fifteen two-fold axes, fifteen mirror planes and a centre of symmetry. Although related to the regular dodecahedron, the pyramidal dodecahedron (see Figure 2b) belongs to a different quasicrystal class, the $\overline{\mathbf{5}} \mathrm{m} \mathbf{2}$, which only contains one five-fold roto-inversion axis, five two-fold axes, five mirror planes and a centre of symmetry. Undoubtedly, the pyramidal dodecahedron is the most peculiar and enigmatic form described by de L'Isle because its derivation cannot be seen as an attempt to approximate a mineral form to any highly regular and symmetric polyhedron (e.g. a Platonic solid). Romé de L'Isle claimed that a number of forms with five-fold symmetry can be observed in some pyrite crystals with variable contents of zinc, copper and other metals, which are frequently called marcassites by de L'Isle, according to previous descriptions by Démeste, (1779). Obviously, Romé de L'Isle could only see approximate forms of these regular solids with pentagonal symmetries. Pyrite has a well-known crystal structure and its external pentagonal forms can only be the result of a singular combination of crystal faces. It 
was not until the end of the twentieth century that the existence of solids with both external and internal pentagonal symmetries (i.e. quasicrystals), was reported (see Figure 3).

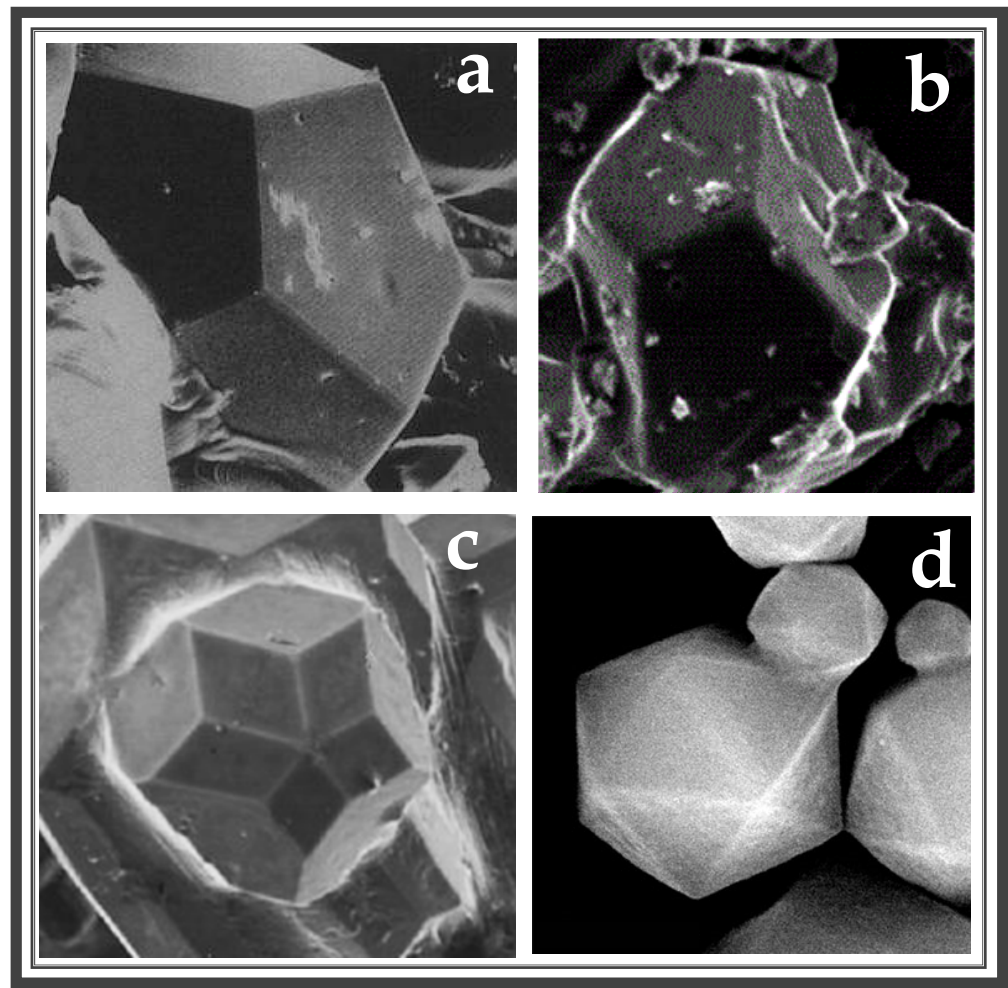

\section{Figure 3}

Scanning electron microcopy images of quasicrystals. a, $\mathrm{Al}_{65} \mathrm{Cu}_{20} \mathrm{Fe}_{15}$ dodecahedral quasicrystal (reproduction from JJAP, Vol. 26, $\mathrm{N}^{\circ}$ 9, pp. L1505-1507; Tsai et al., 1987). b, $\mathrm{Al}_{62,2} \mathrm{Cu}_{25,3} \mathrm{Fe}_{12,5}$ quasicrystal with the shape of an elongated dodecahedron (reproduction from J. Chem Eng Process Technol, 5:2, 1000187; Jamshidi et al., 2014). c, Al-Cu-Fe quasicrystal with the shape of a regular triacontahedron (reprinted by permission from McGraw-Hill Education. Concise Encyclopedia of Physics (2005). ISBN 0071439552). d, icosahedral silica quasicrystal (reprinted by permission from Macmillan Publishers Ltd: Nature. Alfons van Blaaderen, Quasicrystals from nanocrystals, Nature 461, 892-893. Copyright 2009).

Usually, quasicrystals are more or less more or less complex synthetic metal alloys whose external morphologies are astonishingly similar to those reported by Romé de L'Isle. Interestingly, Romé de L'Isle, after studying and idealising the external forms of numerous natural crystals, implicitly assumed that forms with pentagonal symmetries could be found in nature (e.g. the pyramidal dodecahedron shown in Figure 1 is a baked clay model created after a single crystal of marcassite belonging to de L'Isle's personal mineral collection). Furthermore, he recognized that some forms with pentagonal faces could be obtained by 
truncating, bevelling and distorting the corners and faces of a cube in various ways. This is not a trivial crystallographic observation since the $2 / m^{35}$ and the $\overline{5} m z$ quasicrystal symmetry classes share a number of symmetry elements with the $4 / m \overline{3} 2 / m$ cubic crystal class, which contains four three-fold roto-inversion axes, three four-fold axes, six two-fold axes, nine mirror planes and a centre of symmetry. Topological studies have demonstrated that cubic lattices and icosahedral quasilattices are closely related (Torres et al., 1989). In fact, a cubic lattice and an icosahedral quasilattice can be considered two different threedimensional projections or "shadows" of a six-dimensional hypercubic lattice (Mackay, 1990). This means that periodic and quasiperiodic ordering of atoms in solid matter are symmetry-related alternatives to fill the space in the most efficient way. Although Romé de L'Isle did not know anything about the topological relationships between icosahedral quasilattices and cubic and hypercubic lattices, such veiled relationships somehow induced him to consider forms with pentagonal symmetries as plausible forms shown by natural solids. The result was that Romé de L'Isle included in his book Cristallographie (1783), and in the accompanying collection of clay pieces, three-dimensional forms corresponding to quasicrystals whose existence was only recognised two centuries later: an interesting case of scientific premonition.

\section{Acknowledgements}

We thank Toya Legido for photographs shown in Figure.1. Copies of the original plates by Romé de L’Isle were kindly provided by the Historical Library “Marqués de Valdecilla” at the Complutense University of Madrid.

\section{References}

Amorós, J. L. (1978) La gran aventura del cristal. Naturaleza y evolución de la Ciencia de los cristales. E-Prints Complutense. http://eprints.ucm.es/33677/ (In Spanish).

Barlow, W. (1883). Nature, 29, 186-188.

Bravais, A. (1850). Journal de l'École polytechnique, 19-33, 1-128 (In French). 
Concise Encyclopedia of Physics. (2005). McGraw-Hill Education., ISBN 007143955210.

Démeste, J. (1779). Lettres du Docteur Démeste au Docteur Bernard. Sur la Chymie, la Docimasie, la Cristallographie, la Lithologie, la Minéralogie et la Physique en général. Tome Second. (Chez: Didot, Imprimeur de Monsieur, et Clousier, Imprimeur \& Libraire. Paris. (In French).

Fedorov, E. S. (1891). Verhandlungen der Russisch-Kaiserlichen Mineralogischen Gesellschaft zu St. Petersburg, 2 (28), 1-145 (In German).

Friedrich, W., Knipping, P. \& Laue, M. (1912). Sitzungsber. K. Bayer. Akad. Wiss. Math. Phys. Kl, 303-322 (In German).

Hessel, J. F. Ch. (1830). Gehler's Physikalisches Wörterbuch, 7 (I-K), 1023-1340 (In German).

Hessel, J. F. Ch. (1897). Krystallometrie, oder Krystallonomie und Krystallographie. Ostwald's Klassiker der exakten Wissenschaften, 88-89 (In German).

Jamshidi, A. L. C. L., Nascimento, L., Rodbari, R. J., Barbosa, G. F., Machado, F. L. A., Pacheco, J. G. A. \& Barbosa, C. M. B. M. (2014). J. Chem Eng Process Technol. 5:2, 1000187.

Kubbinga, H. (2001). L'Histoire du concept de «molécule ». Paris. Springer-Verlag France (In French).

López-Acevedo, V. \& de Dios Celada, N. (2012). Bol. R. Soc. Esp. Hist. Nat. Sec. Geol. 106, 1-23 (In Spanish).

Maciá Barber, E. (2010). Aperiodic Structures in Condensed Matter: Fundamentals and Applications. Taylor \& Francis Group, LLC.

Mackay, A. L. (1990). Nature, 344, 21.

Penrose, R. (1974). Bull. Inst. Maths. Its. Appl. 10, 266-271. 
Rao, K.R.M., Rao, P.H. \& Chaitany, B.S.K. (2007). Pramana -J. Phys. 68, 481-487.

Romé de L'Isle, J. B. (1783) Cristallographie, ou Description des formes propres a tous les corps du regne minéral, dans l'état de combinaison saline, pierreuse ou métallique, avec figures \& tableaux synoptiques de tous les cristaux connus. (De l'Imprimerie de Monsieur, París) (In French).

Steno, N. (1669). De Solido intra Solidum Naturaliter Contento. Dissertationis Prodromus. $1^{\text {a }}$ Ed. Sub Signu Stellae. Florencia (In Latin).

Sequeiros, L. (2002). Enseñanza de las Ciencias de la Tierra, 10-3, 243-283 (In Spanish).

Shechtman, D., Blech, I., Gratias, D. \& Cahn, J.W. (1984). Phys. Rev. Lett. 53, 1951-1954.

Torres, M., Pastor, G., Jiménez, I. \& Fayos, J. (1989). Phys. Stat. Sol. (b), 154, 439-451.

Schoenflies, A. (1891). Kristallsysteme und Kristallstructur. Leipzig: B.G. Teubner (In German).

Tsai, A. P., Inoue, A. \& Masumoto, T. (1987). Jpn J. Appl. Phys. 26, L1505-L1507.

Van Blaaderen, A. (2009). Nature, 461, 892-893.

Van Smaalen, S. (1995). Crystallography Reviews, 4-2, 79-202.

Weiss, C. S. (1815). Übersichtliche Darstellung der verschiedenen natürlichen Abtheilungen der Krystallisations systeme. Berlin: Akad. der Wiss (In German).

Werner, A. G. (1774). Von den äuserlichen Kennzeichen der Fossilien. Crusius. Leipzig (In German). 